\title{
Spectrum of hepatofugal collateral pathways in portal hypertension: an illustrated radiological review
}

\author{
Ankur Arora $^{1} \cdot$ S. Rajesh $^{1} \cdot$ Yamini S. Meenakshi $^{1} \cdot$ Binit Sureka $^{1} \cdot$ Kalpana Bansal $^{1}$. \\ Shiv Kumar Sarin ${ }^{2}$
}

Received: 7 May 2015 / Revised: 25 June 2015 / Accepted: 29 June 2015 /Published online: 4 September 2015

(C) The Author(s) 2015. This article is published with open access at Springerlink.com

\begin{abstract}
The purpose of this article is to describe the various portosystemic collateral pathways pertinent to portal hypertension on multi-detector row computed tomography (MDCT) and their clinical relevance, with special emphasis on the uncommon ones. The knowledge and understanding of the various patterns of portosystemic collateral channels has important implications both for the clinician and the interventionist. MDCT with its advanced post processing capabilities can exquisitely demonstrate these vascular pathways to help in therapeutic decision making.

Teaching points

- Portosystemic collaterals are an important cause of bleeding and hepatic encephalopathy.

- Radiologists should be familiar with the imaging findings to effectively identify them.

- Pre-operative knowledge of portosystemic collaterals is essential to avoid inadvertent vascular injury.
\end{abstract}

S. Rajesh

rajesh387@gmail.com

Ankur Arora

aroradrankur@yahoo.com

Yamini S. Meenakshi

yaminipratap@gmail.com

Binit Sureka

binitsurekapgi@gmail.com

Kalpana Bansal

dr.kalpana.j@gmail.com

Shiv Kumar Sarin

shivsarin@gmail.com

1 Department of Radiology, Institute of Liver \& Biliary Sciences, D-1 Vasant Kunj, New Delhi 110070, India

2 Department of Hepatology, Institute of Liver \& Biliary Sciences, D-1, Vasant Kunj, New Delhi 110070, India
Keywords Collateral pathways $\cdot$ Multi-detector row computed tomography $\cdot$ Portal hypertension $\cdot$ Shunt $\cdot$ Varices

\section{Introduction}

Portal hypertension (PHTN), characterized by a pathological increase in the portal venous pressure, is one of the key consequences of liver cirrhosis [1]. It results from a combination of increased intrahepatic vascular resistance and augmented blood flow through the portal venous system [1]. This highpressure hepatopetal flow is redirected through alternative pathways into the low-pressure systemic veins, leading to formation of an extensive network of portosystemic collateral vessels (PSCV) [2]. Detection of these 'spontaneous' PSCV serves as an important tool in diagnosing portal hypertension and predicting prognosis [3]. The radiological appearances of the common PSCV, including gastro-oesophageal and paraoesophageal collaterals, gastrorenal or splenorenal shunts, and paraumbilical shunts have been studied at length [4-8]. However, with the advent of multi-detector row computed tomography (CT), unusual pathways of portosystemic anastomoses are increasingly being recognized, yet have not been well described in the literature [9-14]. Since these shunts could be an important cause of variceal bleeding and hepatic encephalopathy, their accurate identification is imperative in therapeutic decision making. In addition, understanding their anatomy may help to avoid potential complications related to interventional radiological procedures and surgery. The purpose of this review is to appraise the spectrum of common and uncommon collateral pathways of the portal venous system that can be encountered in PHTN at CT examinations.

Embryologically derived anastomoses between the portal and systemic circulation exist at various sites in normal healthy humans [3] (Table 1). 
Table 1 Normal sites of portosystemic anastomoses

\begin{tabular}{lll}
\hline Sites & Portal component & Systemic component \\
\hline Lower oesophagus & Left gastric vein & Oesophageal veins \\
Rectum and anal canal & Superior rectal vein & Middle and inferior rectal veins \\
Umbilicus & Paraumbilical veins & Superior and inferior epigastric veins \\
Bare area of liver & Portal venous branches & $\begin{array}{c}\text { Inferior phrenic and right internal } \\
\text { thoracic vein }\end{array}$ \\
Retroperitoneum & Tributaries of splenic and & Renal, suprarenal, paravertebral \\
pancreatic and colic veins & and gonadal vein \\
Patent ductus venosus (rare) & Left branch of portal vein & Inferior vena cava (IVC) \\
\hline
\end{tabular}

In PHTN, dilatation of these channels leads to formation of varices at various sites in the body, which are mostly classified into two groups, the gastro-oesophageal varices and ectopic varices [3] (Fig. 1). These varices are fed in the long term by spontaneous development of large shunts in the abdomen, which can be anatomically divided into intrahepatic, transhepatic and extrahepatic shunts [9-12] (Fig. 1).

\section{Varices}

\section{Oesophageal and para-oesophageal varices}

Oesophageal varices are detected in about $50 \%$ of patients with liver cirrhosis and approximately $5-15 \%$ of cirrhotics show newly formed varices or worsening of varices each year [15-17]. The term oesophageal varices usually refers to the dilated veins located within the wall of the lower oesophagus, whereas para-oesophageal varices are situated outside the wall of the oesophagus (Fig. 2). Oesophageal varices are usually supplied by the anterior branch of the left gastric vein, whereas the posterior branch of this vein directly forms the para-oesophageal collateral vessels [6] (Fig. 3).

Blood from the oesophageal varices usually drains into the left subclavian vein and/or brachiocephalic vein, while the blood of the para-oesophageal varices commonly drains into the azygos or hemiazygos system (Fig. 4). The oesophageal or para-oesophageal varix may rarely drain into the inferior vena cava (IVC) $[3,5]$.

Oesophageal varices are the most common to bleed in cirrhotic patients, owing to the high-volume of blood carried by them, and account for the high mortality associated with spontaneous variceal bleeding [16].

\section{Gastric and perigastric varices}

Gastric varices (GV) (Fig. 5) are less prevalent than oesophageal varices, being present in 5 to $33 \%$ of patients with portal hypertension. They have a reported incidence of bleeding of about $25 \%$ in 2 years [18-20]. They are classified and graded on endoscopy by various authors. Currently, the most commonly used classification is the Sarin's classification [18], which divides the GV into gastro-oesophageal (GOV) and isolated gastric varices (IGV). GOV are basically oesophageal varices that extend beyond the oesophagogastric junction and are further subdivided into GOV1, which extend for $2-5 \mathrm{~cm}$ along the lesser curvature, and GOV2, which extend along the fundus. IGV, as the name suggests, are not associated with oesophageal varices and are divided into IGV1, which are located in the fundus, and IGV2, present anywhere other than the fundus including the body, antrum or pylorus. GV are supplied by a single or multiple afferent gastric veins, commonly the left and posterior gastric veins, but are also seen with the short gastric veins, and rarely the gastroepiploic vein, which typically supplies the varices after endovascular or surgical exclusion of other main afferent veins [3] (Fig. 6). There are usually several short gastric veins that course along the greater curvature on the medial side of the spleen to empty into the splenic vein. [3] The posterior gastric vein is a distinct vein localised between the left and short gastric veins that runs superiorly in the retroperitoneum and gastrophrenic ligament and joins GV . GOV1 are formed by the anterior branch of the left gastric vein, and penetrate the gastric wall at the level of the cardia. GOV2 and IGV1 are usually fed by the short gastric and posterior gastric veins and commonly drain into the oesophageal or para-oesophageal veins (approximately $84 \%$ ) [3]. They may also drain into the left renal vein by way of gastrorenal shunt, or directly into the IVC through a gastrocaval shunt via the left inferior phrenic and pericardiophrenic vein [3, 21, 22] (Fig. 6). Other smaller venous pathways include ascending lumbar vein, perivertebral venous plexus, intercostal veins, and rarely, the azygos vein [3].

The risk of bleeding from gastric varices is known to be lower than that from oesophageal varices, however, the severity of bleeding and the associated mortality is significantly higher, because of their large size and rapid blood flow [23]. Various treatment modalities, such as pharmacotherapy, balloon tamponade, endoscopic procedures, endovascular treatment, and surgery, have been used in their management [24-26]. For patients in whom endoscopic therapy fails to control the GV bleed or who re-bleed, interventional radiological techniques such as transjugular intrahepatic portosystemic shunt (TIPS), balloon-occluded retrograde obliteration of 


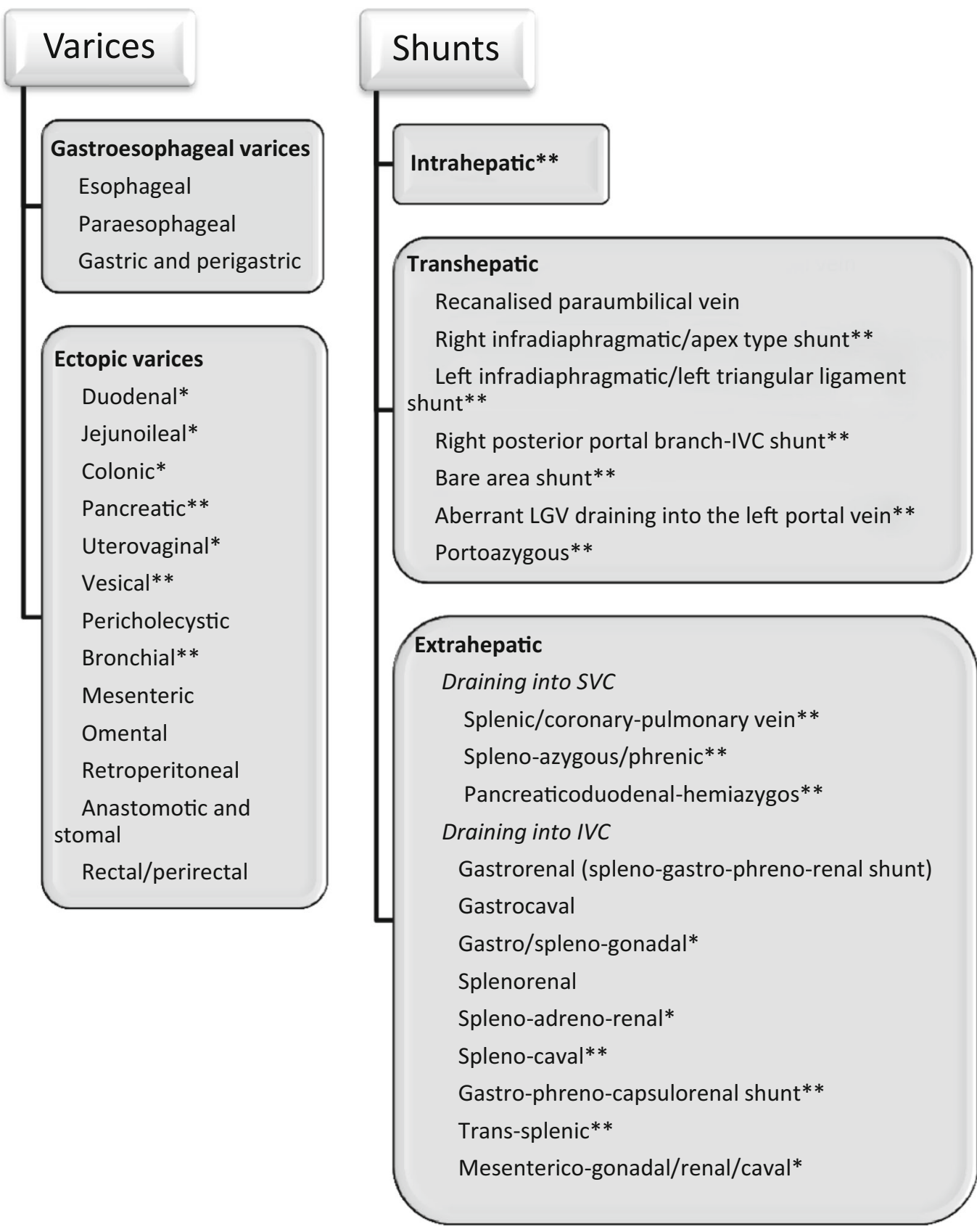

\section{*Uncommon \\ **Rare}

Fig. 1 Portosystemic collateral pathways described in English-language medical literature

varices (B-RTO) or percutaneous transvenous embolisation (PTVE) of varices can be done [20, 23, 25]. In majority of the cases, the anatomy of varices dictates the approach used for treatment. Familiarity with the afferent and efferent veins is of paramount importance, as the degree of difficulty in performing endovascular obliteration of gastric varices and the success of the procedure are directly correlated with the anatomic complexity of the varix .

\section{Ectopic varices}

Ectopic varices account for 2-5\% of gastrointestinal tract variceal bleeding [27-29]. However, they have a fourfold increased risk of bleeding when compared with oesophageal varices, and can have a mortality rate as high as $40 \%$ [28-32].

Ectopic varices can either be a result of global portal hypertension or splanchnic venous occlusion. These occlusions 


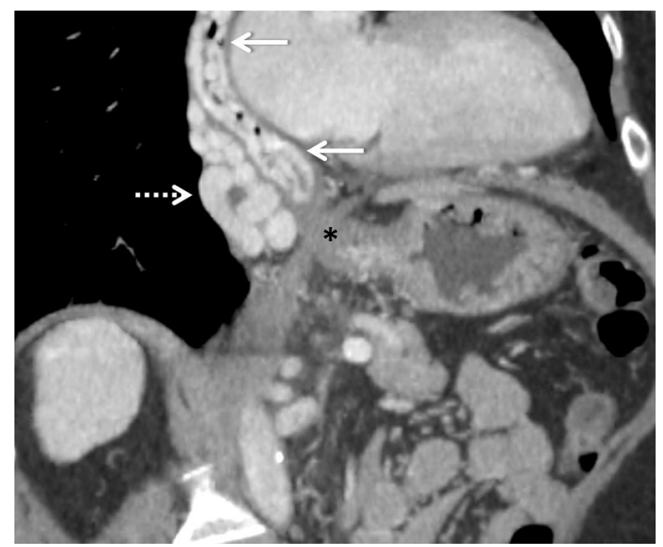

Fig. 2 Coronal-oblique maximum intensity projection (MIP) contrastenhanced CT (CECT) image demonstrating multiple collaterals in the oesophageal mucosa (solid arrows) and para-oesophageal region (interrupted arrow). Asterisk denotes the gastro-oesophageal junction

can be due to thrombosis of the main portal vein, splenic vein, mesenteric veins or of a spontaneous gastrorenal shunt (post B-RTO) [7]. The occlusion can also be due to postoperative adhesions, scarring, and postoperative-altered anatomy [27, $31]$.

The standard management of ectopic varices has not yet been established. However, it is known that when bleeding occurs from ectopic varices, it is difficult to control by any means, and the bleeding is potentially fatal. All treatment strategies and techniques have been utilised in their management, including medical (systemic vasopressin and octreotide) and endoscopic therapy (banding/ligation and injection therapy), decompression using TIPS and partial splenic artery embolisation, antegrade/retrograde obliteration and surgical ligation [27-30, 32-35]. However, all of them have shown poor outcomes, underlining the importance of early diagnosis and therapy of these varices. Better understanding of ectopic varices is needed for a more systemic approach to this rare but menacing problem.

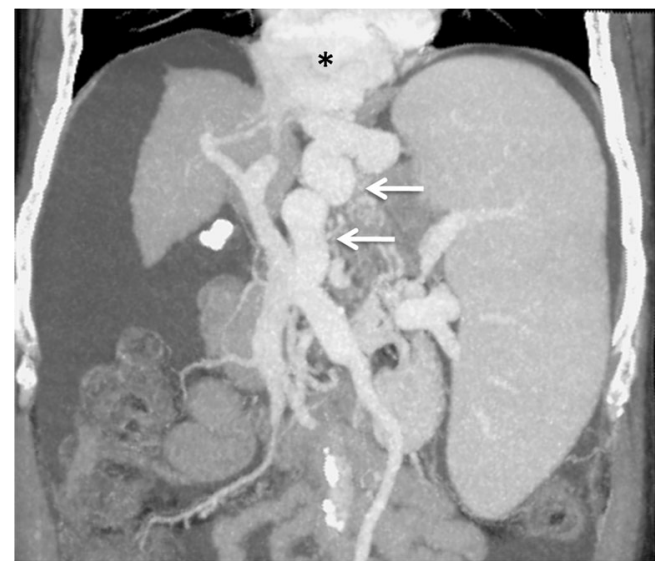

Fig. 3 .Coronal MIP image showing a bunch of para-oesophageal collaterals (asterisk) being supplied by a dilated left gastric vein (arrows)

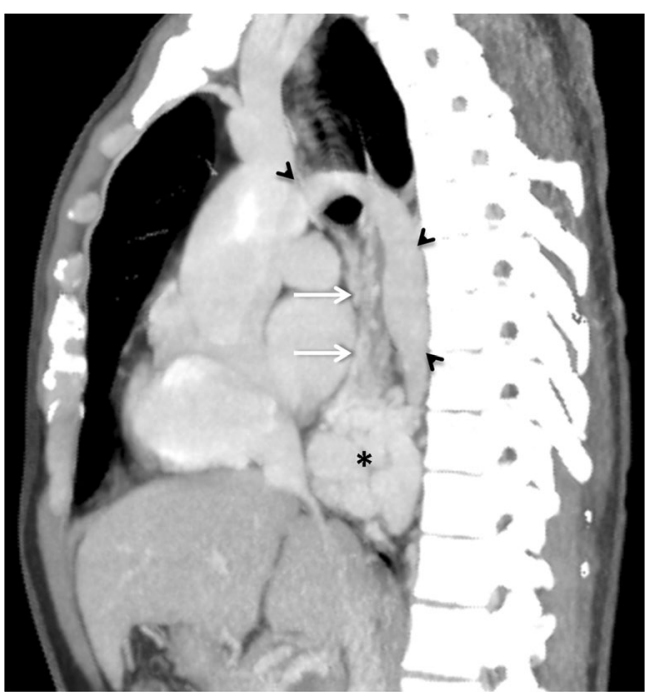

Fig. 4 Sagittal MIP image from another patient demonstrating multiple oesophageal and para-oesophageal collaterals (arrows and asterisk, respectively) drained via dilated azygous vein (arrowheads)

Duodenal varices (DV) resulting from intrahepatic portal hypertension are rather uncommon accounting for only $1-3 \%$ of all cases [3]. The most common locations of duodenal varices are in the first and second portions of the duodenum (Fig. 7), although they can also be rarely seen in the distal duodenum [7]. The rare occurrence of bleeding from DV, in contrast to oesophageal varices, may be related to their smaller diameter, shorter length and deeper location on the outer wall of the duodenum [3].

The afferent vessel can be formed by any of the tributaries of portal venous system and commonly include the superior and inferior pancreaticoduodenal veins, cystic branches of the superior mesenteric veins, gastroduodenal vein, and pyloric vein $[3,7]$. The efferents flow hepatofugally via retroperitoneal shunts (also called veins of Retzius) into the IVC via the

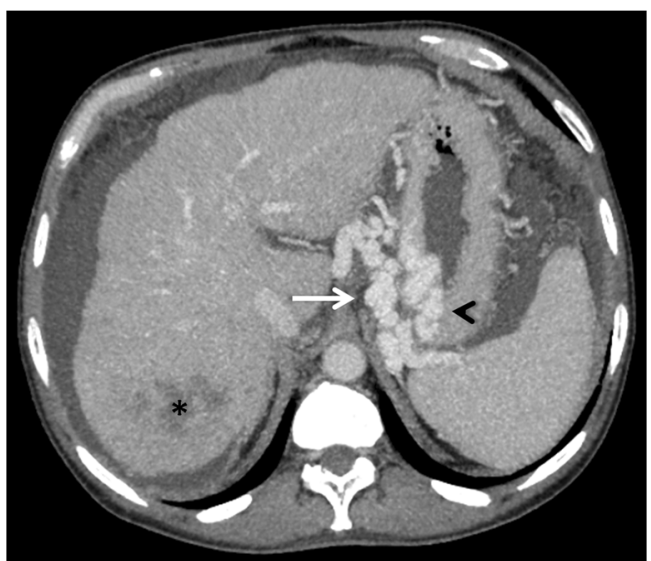

Fig. 5 Axial CECT image showing multiple collaterals in the gastric mucosa (arrowhead) and perigastric region (arrow). The patient also had a right lobe hepatocellular carcinoma (asterisk) 
Fig. 6 Graphic illustration of the Kiyosue classification of $\mathrm{GV}$ [21]. a Classification based on the inflow pathway(s). Type 1 (i) refers to a single afferent vein for the varices, while type 2 (ii) refers to multiple afferent vessels contributing to the varix. Type 3 is like type 2 with the addition of small afferent vein(s) in direct continuity with the outflow tract. b Classification based on drainage pathway. Type A consists of a gastrorenal shunt as the sole drainage. Type B describes the additional presence of small portosystemic collaterals; type $\mathrm{C}$ describes the presence of both a gastrorenal and direct gastrocaval shunt; type D consists of multiple small portosystemic collaterals as the drainage pathways without any recognisable shunt a

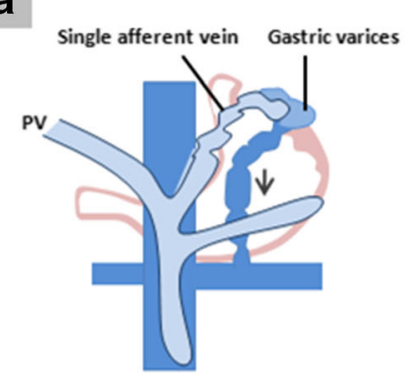

(i)

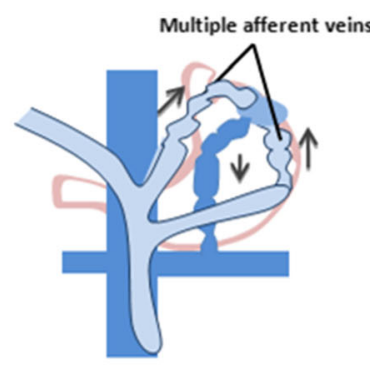

(ii)

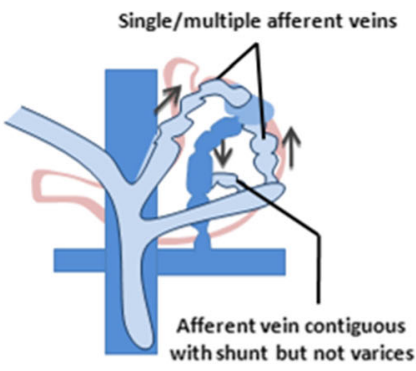

(iii)

\section{b}

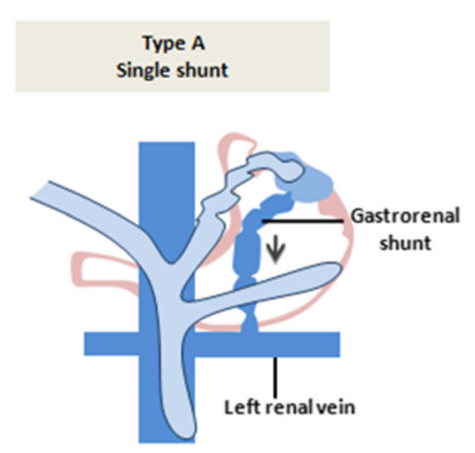

Type B

Single shunt and collaterals
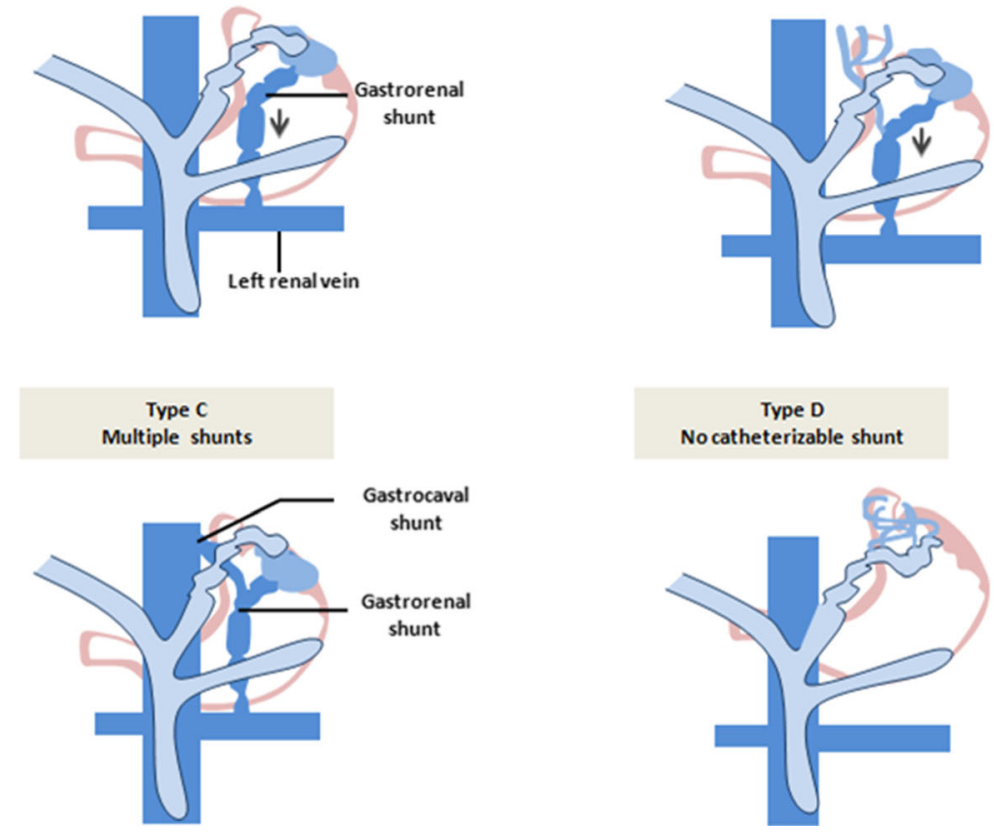

right gonadal veins (mesenterico-gonadal shunt) or the capsular renal veins (mesenterico-renal shunt) [3,7].

Jejunal and ileal varices are frequently associated with prior abdominal surgery [3]. The development of these varices is often due to collateral circulation through postoperative adhesions between the jejunum or ileum and the abdominal wall. Adhesions tend to bring the parietal surface of the viscera in contact with the abdominal wall, and portal hypertension results in the formation of varices [3, 7]. However, they can also be found in portal hypertensive patients without any prior history of surgical interventions (Fig. 8). The afferent vessels include the jejunal and ileal veins (tributaries of superior mesenteric vein) and the efferents generally drain into abdominal wall or the veins of Retzius [3].
Colonic varices are usually found in a segmental distribution, primarily located in the cecum and the rectosigmoid region [3] (Fig. 9). Although rectal varices are a common finding at colonoscopy, isolated varices of the colon are rare [36]. It has been hypothesised that colonic varices due to portal hypertension arise in patients in whom normal embryological colonic anastomoses are highly developed [36]. The afferent vessels include the ileo-colic, right, middle colic or sigmoid colic vein. Efferent veins include the right gonadal vein, right renal vein and systemic lumbar veins [3]. Recognition of this condition is important, as colonic varices may be an infrequent cause of massive lower gastrointestinal bleeding [36, 37]. Although there are reports of successful endoscopic therapy and TIPS, the treatment of colonic varices is not well defined [36, 37]. 


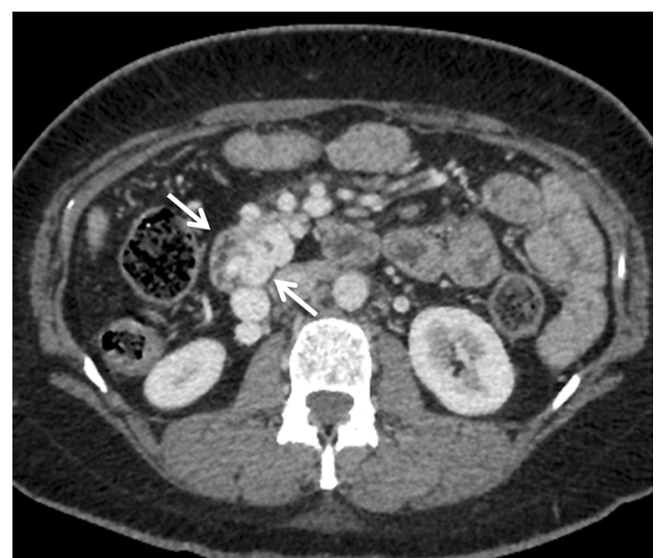

Fig. 7 Axial CECT image showing multiple submucosal as well as paraduodenal collaterals along the third part of duodenum (arrows)

\section{Pancreatic varices}

Pancreatic varices are rare. When present, they are almost always associated with portal vein thrombosis with concomitant thrombosis of the splenic and the superior mesenteric veins (Fig. 10).

\section{Uterovaginal varices}

The uterus and vagina have an extensive network of venous channels that primarily drain into the systemic circulation via the uterine and hypogastric veins. The only communication between this plexus and the portal system is through the superior portion of the haemorrhoidal plexus. While anorectal varices are quite commonly found in cirrhotics, the extensive uterovaginal venous plexus ensures that the effects of portal hypertension are effectively decompressed without the formation of varices [38]. Thus, uterovaginal varices (Fig. 11) are exceptionally rare. To date, there have been only eight reported cases of vaginal variceal haemorrhage [39]. Barring one instance, all these

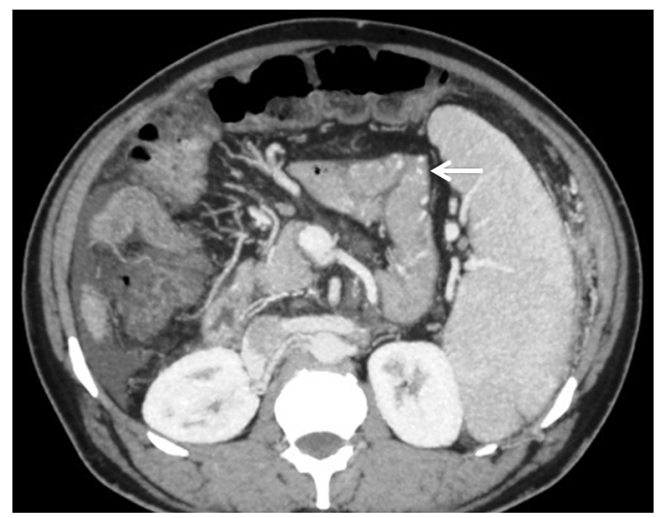

Fig. 8 Axial CECT image showing multiple jejunal collaterals (arrow)

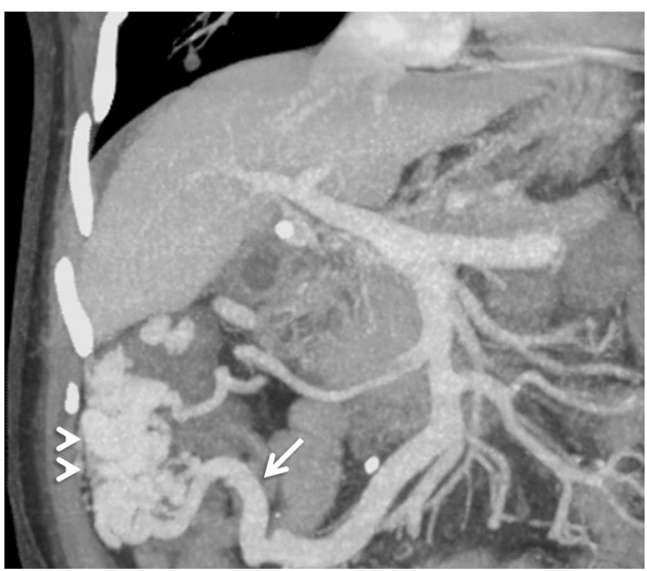

Fig. 9 Coronal MIP image demonstrating multiple pericolonic collaterals (arrowheads) deriving their afferent supply from the superior mesenteric vein (arrow)

cases occurred in patients who had previously undergone hysterectomy, leading to speculation that loss of the uterine venous plexus due to the surgery might be leading to venous congestion in vagina [40]. Massive haemorrhage has been reported to occur from vaginal varices that had to be controlled using suture ligation, banding, or sclerotherapy, together with local tamponade. TIPS has also been reported to be beneficial as a temporizing measure in reducing variceal pressure [38]. However, liver transplantation remains the definitive treatment [38].

\section{Vesical varices}

Vesical varices secondary to portal hypertension are extremely rare, with only a handful of reported cases, since the bladder wall is an unusual collateral route for the venous splanchnic blood [41-43]. They may appear when the usual splanchnic-bed collaterals cannot develop, thus allowing venous blood to flow through the venous system of the bladder [41] (Fig. 12). Generally reported cases of vesical varices have a history of abdominal surgery or

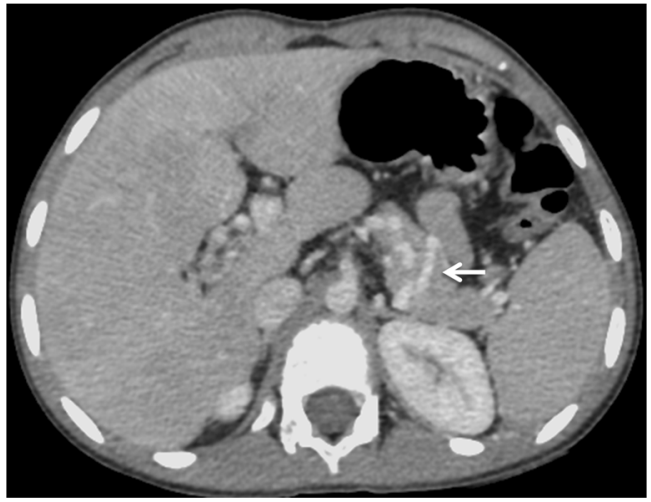

Fig. 10 Axial CECT image showing collaterals in the pancreatic parenchyma (arrow) in a patient with portal vein thrombosis 


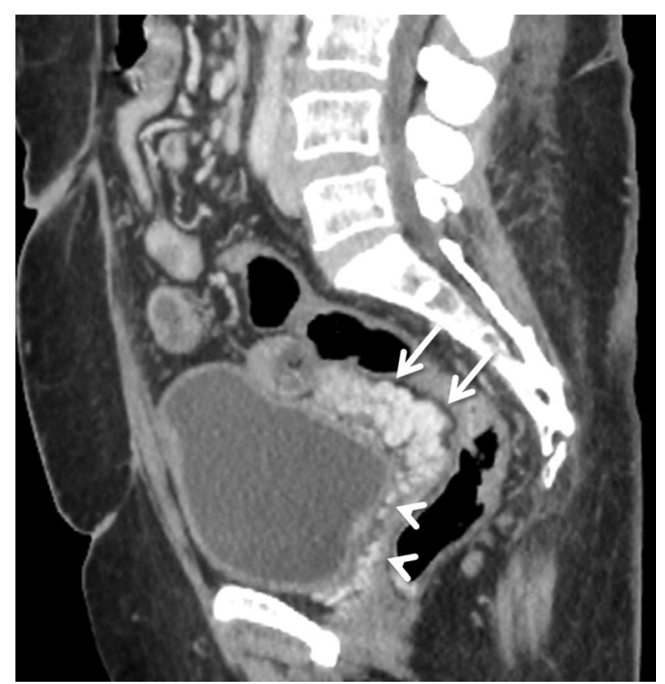

Fig. 11 Sagittal MIP image showing multiple uterine and vaginal collaterals (arrows and arrowheads, respectively)

intervention in the form of sclerotherapy and band ligation, which prevents the development of usual PSCV [41]. Patients may present with gross hematuria necessitating therapy [42].

\section{Pericholecystic varices}

Pericholecystic varices refer to varices in or outside the wall of gallbladder in a pericholecystic location (Fig. 13) $[3,44]$. They are present in approximately $12 \%$ of patients with portal hypertension, but are more frequent in those with extrahepatic portal vein obstruction (30\%) [3]. The afferent veins are the cystic vein or a branch of the right portal vein, while the efferent drain into the hepatic vein,

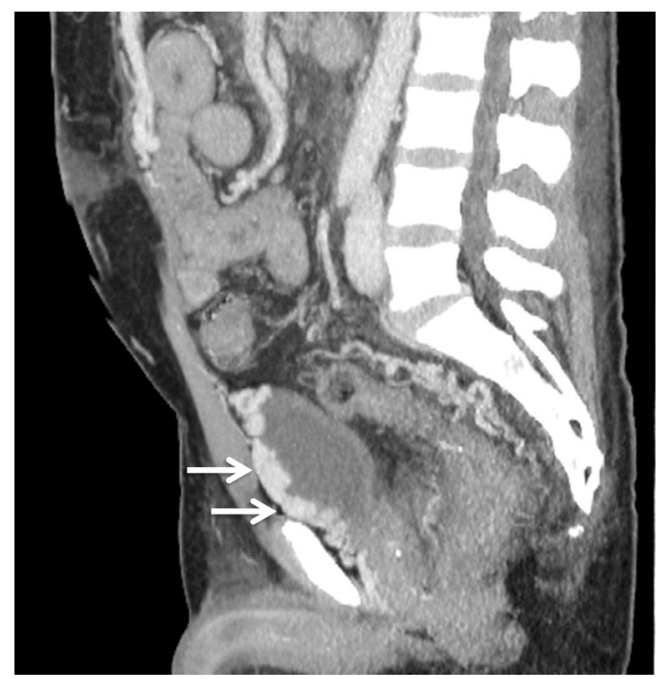

Fig. 12 Sagittal MIP image showing multiple collaterals in the wall of the urinary bladder (arrows)

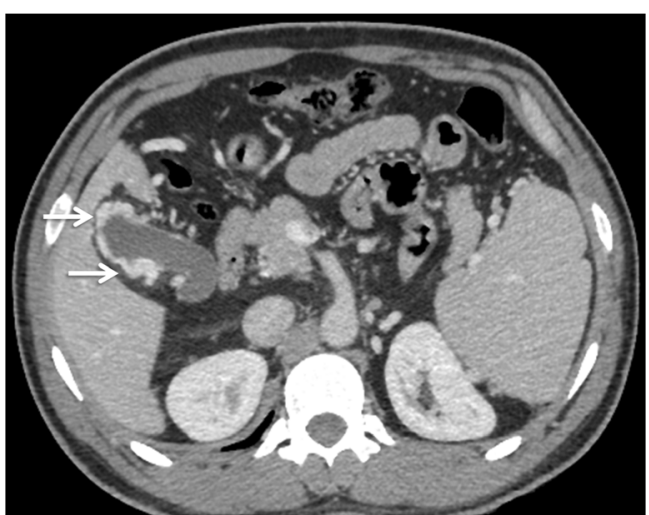

Fig. 13 Axial CECT image showing multiple pericholecystic varices (arrows)

intrahepatic portal vein, or into systemic anterior abdominal wall collaterals [3].

\section{Bronchial varices}

Bronchial varices are speculated to develop through collateral channels which normally exist between the tracheal and oesophageal venous systems [45]. There have been only three case reports in English-language medical literature describing bronchial varices secondary to portal hypertension [45-47]. Two of these were in patients with alcoholic liver cirrhosis and oesophageal varices [46, 47], while the third was secondary to extrahepatic portal vein stenosis [45]. All the previously reported cases presented with hemoptysis. In one of them, the bleeding was massive and required portosystemic shunting and embolisation [47].

\section{Mesenteric collaterals}

Mesenteric collateral vessels may arise from the superior mesenteric vein (SMV) and inferior mesenteric vein (IMV) and ultimately drain into the IVC via the retroperitoneal or pelvic veins (also called the veins of Retzius) [48, 49]. In contrast to other portosystemic shunts, the veins of Retzius are often not dilated even in patients with portal hypertension, and hence are not well recognized. Various pathways of veins of Retzius are defined according to the receiving vein (mesenterico-gonadal/renal/caval or iliac)

\section{Retroperitoneal collaterals}

Retroperitoneal varices are thought to arise from the colic or mesenteric branches (veins of Retzius) and can occur anywhere in the retroperitoneum [3]. Collaterals may develop in the peripancreatic, perisplenic, perirenal, paravertebral (Fig. 14) and retrocaval area. Retroperitoneal collaterals may communicate with retrogastric varices or inferior phrenic vein. They may drain into the renal vein or directly into the IVC [3]. 

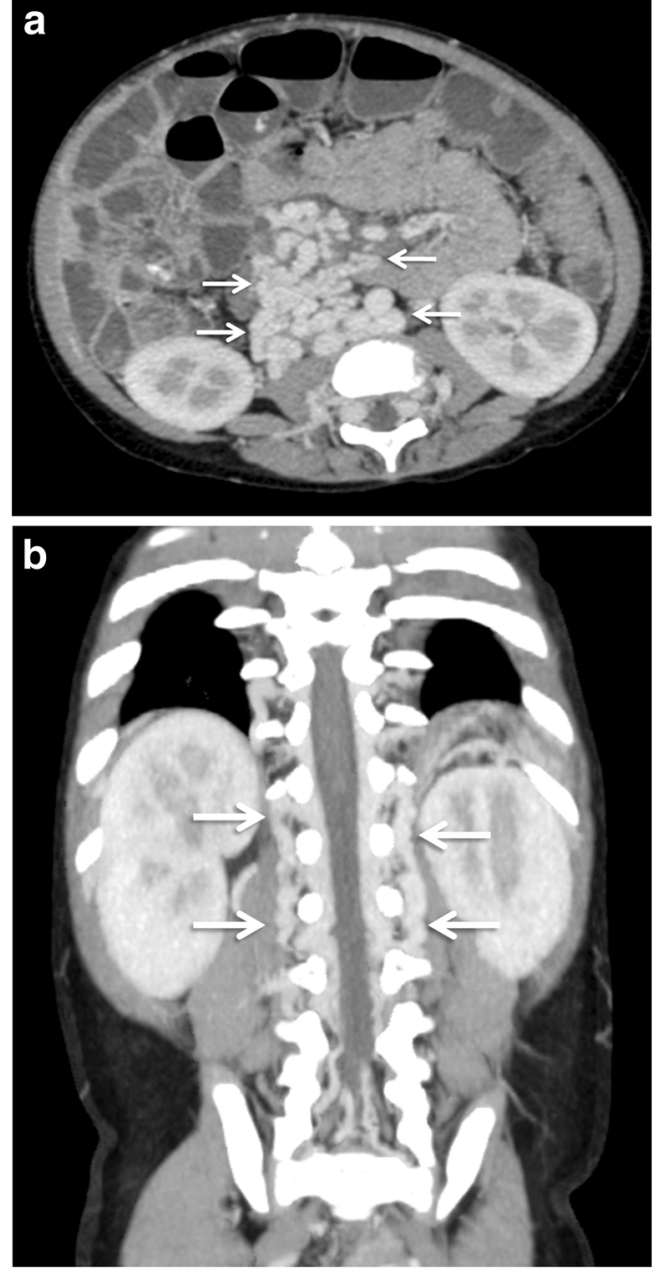

Fig. 14 Coronal MIP image showing multiple retroperitoneal and paravertebral collaterals (arrows in a and b, respectively)

\section{Omental varices}

Omental collateral vessels are infrequently included in the lists of common portosystemic collateral vessels, presumably because they are not well visualized with angiography [6]. However, they can be effortlessly visualised on cross-sectional imaging (Fig. 15). Omental varices arise from the superior or inferior mesenteric veins and drain into the retroperitoneal or pelvic veins [3]. Occasionally they may drain into the gastrooesophageal varices. The greater omentum, in contrast to the small bowel mesentery, has scanty vascular structures. In patients with portal hypertension and ascites, omental varices may mimic omental infiltration from carcinomatosis or peritonitis. More importantly, there have been reports of fatal episodes of bleeding from rupture of omental varices [50, 51]. Mortality remains high despite surgical correction of the bleeding underlining the importance of early detection and prompt surgical intervention.

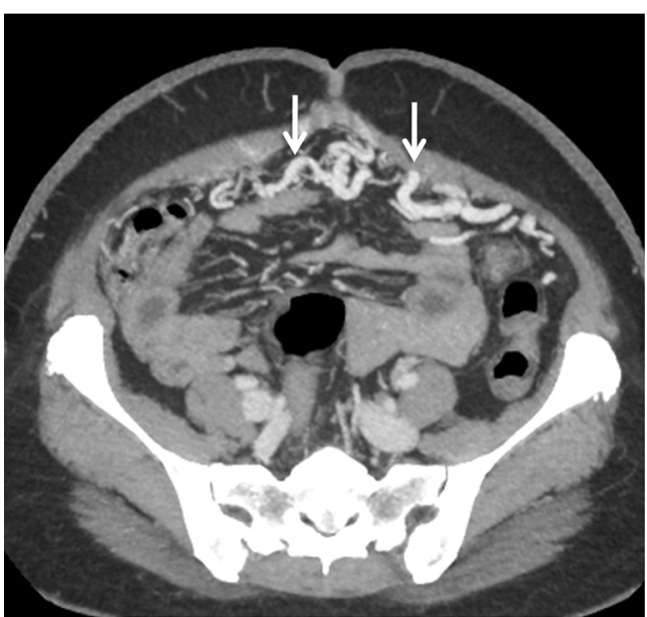

Fig. 15 Axial MIP image showing multiple omental collaterals (arrows)

\section{Anastomotic and stomal varices}

In the setting of chronic portal vein thrombus, collaterisation usually occurs through the hepaticoduodenal ligament, resulting in the formation of a portal cavernoma. However, in patients who have undergone previous hepatobiliary surgery, formation of the classical portal cavernoma can be precluded by the surgical dissection of preformed primitive vascular structures in the hepatoduodenal ligament [3]. In these patients, collateral channels can develop at unusual locations. Previously described entities include porto-portal varices in patients with enteroenteric anastomosis [52] and dilated communicating channels between jejunal veins and intrahepatic portal vein branches in patients with hepaticojejunostomy [53].

Surgically created bowel stomas create a communication between the high pressure portal venous network of the mesentery and the low pressure network of systemic veins in the abdominal wall, resulting in formation of stomal varices (Fig. 16). Approximately $50 \%$ of patients with surgical digestive stoma in a context of portal hypertension have stomal varices [3].

\section{Rectal and perirectal varices}

Rectal varices constitute a pathway for portal venous flow between the superior rectal veins of the inferior mesenteric system and the middle and inferior rectal veins of the iliac system and manifest as discrete dilated submucosal veins [3, 54] (Fig. 17). The superior rectal vein drains into the extrinsic rectal venous plexus (ERVP), which lies outside rectum. From the ERVP, the blood flows through the muscularis propria into the intrinsic rectal venous plexus (IRVP), which consists of a superior group lying in the rectal submucosa and an inferior group lying in the corresponding anal subcutaneous tissue. 


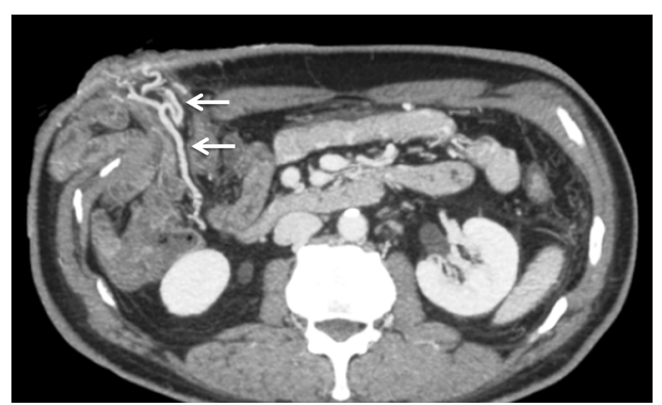

Fig. 16 Axial MIP image showing stomal collaterals (arrows)

Rectal varices are formed from this superior group of submucosal veins of IRVP. The inferior group of IRVP forms the inferior rectal vein and contributes to formation of external haemorrhoids. Portal blood from both ERVP and IRVP drains into the systemic circulation through the recto-genital and inter-rectal portosystemic shunts.

For a surgeon considering an anorectal surgery, these collaterals are of special clinical concern, because an anorectal anastomosis through the inferior mesenteric vein can potentially cause catastrophic haemorrhoidal bleeding.

\section{Shunts}

\section{Intra-hepatic shunts}

Intrahepatic portosystemic venous shunts (IPSVS) can be either congenital due to persistent embryonic venous anastomoses, or acquired due to cirrhosis, traumatic episodes, or rupture of a portal venous aneurysm into a hepatic vein. Based on the published case reports of IPSVS, Park et al. classified them

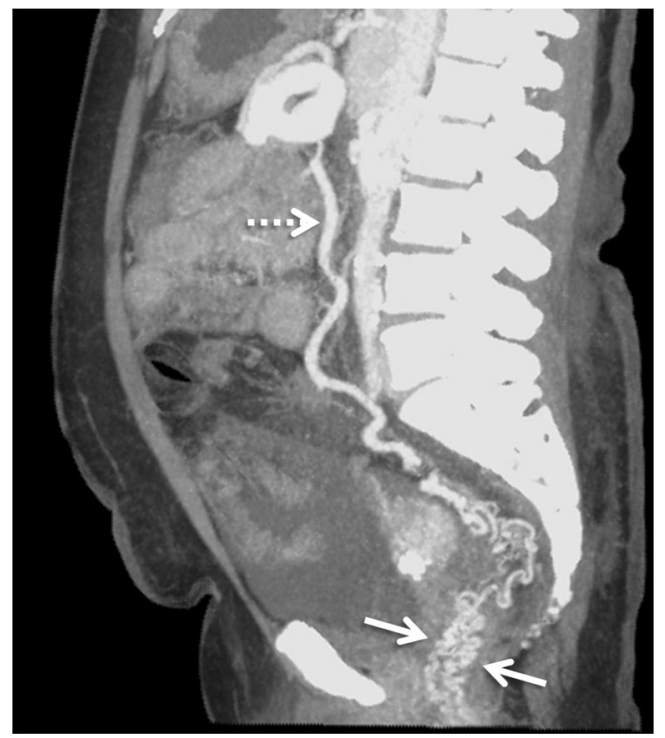

Fig. 17 Sagittal MIP image showing multiple rectal collaterals (arrows) deriving their afferent supply from the IMV (interrupted arrow) into the following types: (1) single tubular shunt connecting the right portal vein to the inferior vena cava (most common type) (Fig. 18), (2) localized peripheral shunt in which one or more communications are found in a single hepatic segment, (3) portosystemic shunt through a portal vein 'aneurysm' and (4) multiple communications between peripheral portal and hepatic veins in several segments [55]. Their clinical significance lies in the fact that multiple or large IPSVS can result in the development of hepatic encephalopathy that might need to be treated by radiological intervention [56]. Also, this collateral pathway can preclude crucial procedures such as TIPS. In addition, type 1 and 3 IPSVS may mimic a hypervascular lesion like hemangioma on conventional CECT [10].

\section{Transhepatic shunts}

Transhepatic PSCV involve intrahepatic branches of the portal vein that communicate with a systemic vein outside the liver, including the inferior vena cava, coronary vein, vertebral plexus, and hemiazygos vein [10]. In 1883, Sappey described accessory portal veins in the suspensory ligament entering the liver capsule through different locations, such as the vessels located at the falciform ligament through which the anterior parietal veins communicate with the left branch of the portal vein (Table 2) [57, 3]. These vessels play an important role in the origin of transhepatic portosystemic shunts $[3,10]$.

\section{Recanalised paraumbilical vein}

The paraumbilical veins, also called inferior veins of Sappey, are the most common type of transhepatic shunts that accompany ligamentum teres (obliterated left umbilical vein) in the falciform ligament [3]. Paraumbilical vessels may anastomose with the superior epigastric or internal thoracic veins and drain into the superior vena cava (SMV), or anastomose with the inferior epigastric vein and then drain into the IVC through the external iliac vein [48] (Fig. 19). The development of large recanalised paraumbilical vein has been found to prevent formation of bleeding oesophageal varices and to predispose to hepatic encephalopathy [58].

Table 2 Accessory portal veins described by Sappey

\begin{tabular}{ll}
\hline Site & Veins \\
\hline Upper part of falciform ligament & $\begin{array}{l}\text { Superior veins of Sappey } \\
\text { Lower part of falciform ligament }\end{array}$ \\
Bare area of liver & Diaphragmatic veins \\
Left triangular ligament & Left inferior phrenic vein \\
& and intercostal vein \\
Right triangular ligament & Right inferior phrenic vein \\
Gastrohepatic omentum & Cystic veins and branches \\
& of LGV \\
\hline
\end{tabular}




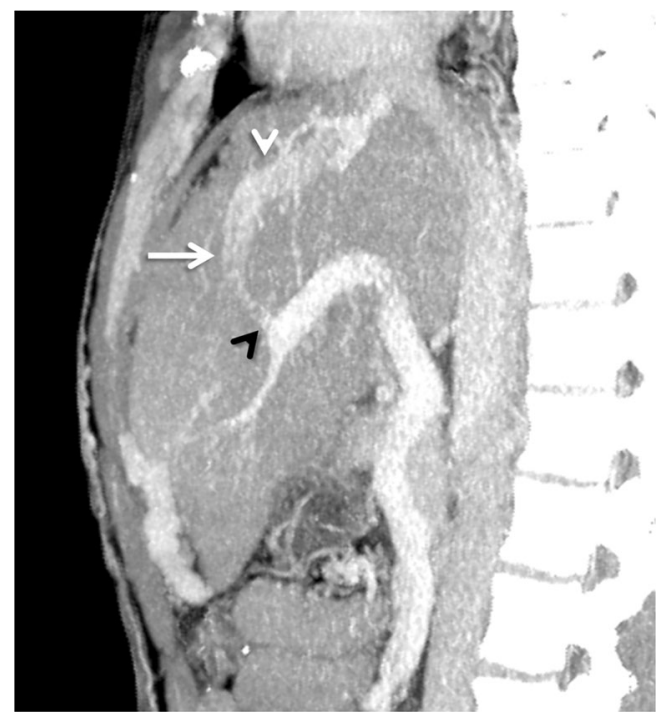

Fig. 18 Sagittal MIP image showing an intrahepatic shunt (arrow) between the right portal vein (black arrowhead) and IVC (white arrowhead)

Occasionally, collateralisation can occur between a giant tortuous recanalised paraumbilical vein and the veins of the anterior abdominal wall (Fig. 20). This results in formation of a network of dilated periumbilical veins ('medusa head' appearance) known as Cruveilhier-Baumgarten syndrome manifesting clinically as abdominal wall bruit (the CruveilhierBaumgarten bruit) and a palpable thrill $[58,59]$.

In the presence of prominent anterior abdominal wall collaterals, a seemingly innocuous procedure like paracentesis could cause serious complications, if done without imaging guidance. Similarly, in the presence of abdominal wall or paraumbilical collaterals, even a simple hernia operation can become a dreaded procedure. Even with knowledge of a recanalised paraumbilical vein, the true extent and complexity may be underestimated without explicit information about its course and size. More recently, recanalised paraumbilical vein has been used as an access route for percutaneous embolisation of bleeding gastro-oesophageal and umbilical varices [60, 61].

\section{Right infradiaphragmatic shunt/ apex type shunt}

In the right infradiaphragmatic shunt, the collateral vein arising from a peripheral branch of left portal vein drains into the internal thoracic vein and the intercostal vein $[10,11]$. This vein is also called the superior vein of Sappey [10]. The hepatofugal blood directed through this shunt into the internal thoracic vein reaches the right heart via the brachiocephalic vein and the SVC. In patients with SVC syndrome, contrast medium or isotopes injected into the arm go into the liver through this shunt, explaining the "hot" spot that is sometimes shown in the liver of these patients $[10,62]$.

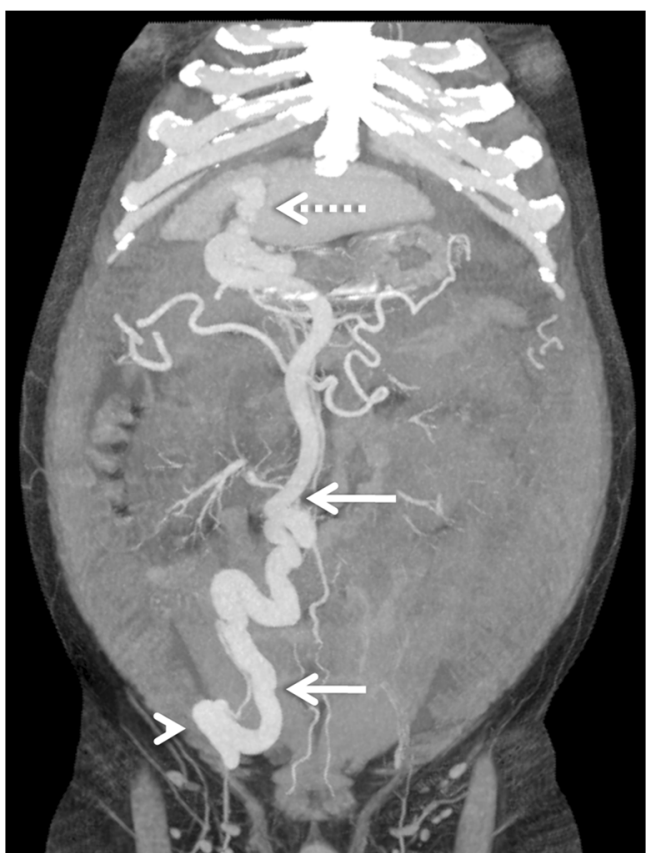

Fig. 19 Coronal MIP image showing a dilated and tortuous recanalised paraumbilical vein (solid arrows) arising from the left portal vein (interrupted arrow) and draining into the right common iliac vein (arrowhead)

\section{Left infradiaphragmatic shunt/left triangular ligament shunt}

In this type of the shunt, the collateral vein arising from the peripheral portal branch of the left lateral segment communicates with the left inferior phrenic vein at the left triangular ligament, and drains into the IVC or the left renal vein through the intercostal vein or the left pericardiophrenic veins $[10,11]$ (Fig. 21).

\section{Right posterior portal branch-inferior vena cava (IVC) shunt}

Dilated collateral vessel arising from the right posterior portal vein runs across the posterior surface of the liver, forms a venous aneurysm outside the liver, and drains into the IVC directly or through the adrenal vein [10-12].

\section{Bare area shunt}

The peripheral branch of the right posterior portal vein runs across the surface of the liver and drains into the intercostal vein or the right inferior phrenic vein. In contrast to the right posterior portal vein type described previously, the vein does not show aneurysmal dilatation in the bare area type [10] (Fig. 22).

\section{Aberrant left gastric vein draining into the left portal vein}

The left gastric vein usually drains the cardiac region of the lesser curvature of the stomach, and normally joins the spleno- 


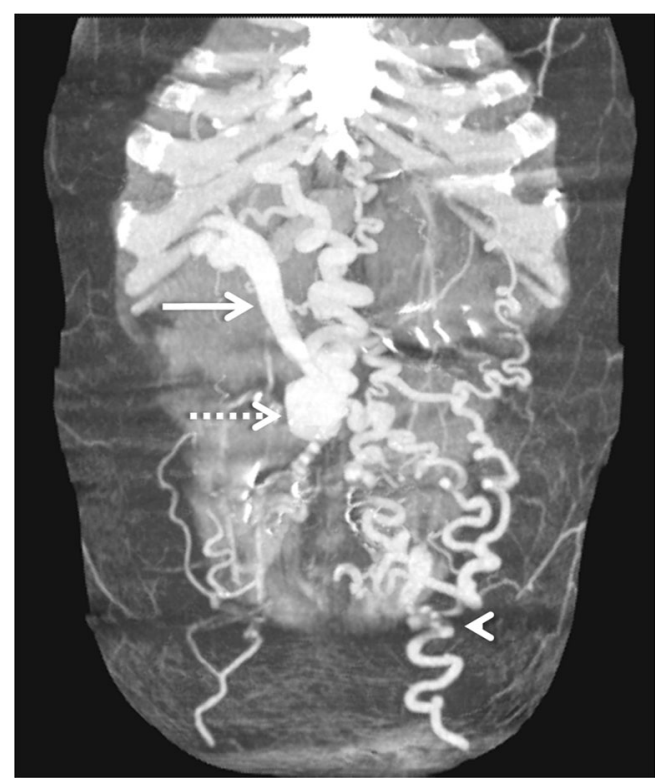

Fig. 20 A giant recanalised paraumbilical vein draining via a large tuft of periumbilical varices (interrupted arrow) into the ipsilateral internal thoracic vein (solid arrow) as well as contralateral superficial epigastric vein (white arrowhead)

portal confluence. The aberrant left gastric vein runs along the hepatogastric ligament and directly drains into the left portal vein [11], thus serving as hepatofugal collateral from the portal vein to systemic circulation (Fig. 23). This variant is of great relevance to the interventional radiologist as inadvertent leakage of sclerosant into the portal circulation during procedures such as B-RTO carries the risk of intrahepatic and extrahepatic portal venous thrombosis.

\section{Portoazygos shunt}

This refers to a communication between the main portal and the azygos veins. While congenital portoazygos shunts

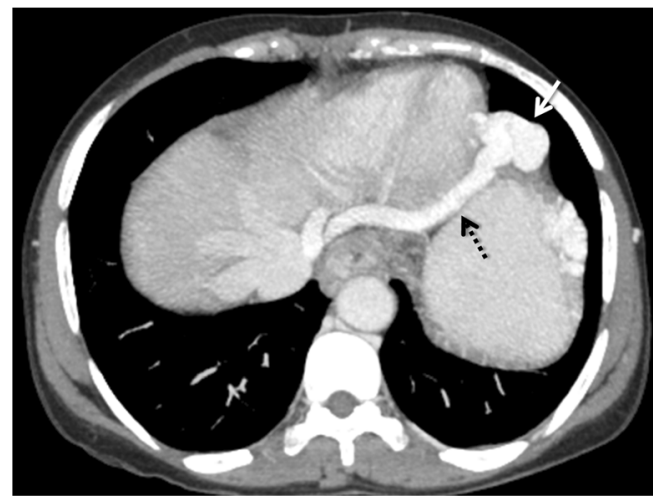

Fig. 21 Left infradiaphragmatic shunt. A transhepatic shunt (interrupted arrow) wherein the collateral vein from the peripheral portal branch of the left lateral segment communicates with the left inferior phrenic vein at (solid arrow) the left triangular ligament have been extensively described in certain dog breeds [63], it is rare in humans, with only a single case report describing this entity in a neonate with thoraco-abdominal duplication and absent intrahepatic portal vein [64]. Its description in association with liver cirrhosis and portal hypertension is also limited to a solitary case report. In this report, the shunt was seen between the posterior aspect of the main portal vein and the azygos vein along the right aspect of the thoracolumbar vertebrae [13]. It may be asymptomatic, but can cause hepatic encephalopathy or variceal bleeding. Treatment options include endovascular transvenous coil embolisation or surgical ligation [13].

\section{Extrahepatic shunts}

\section{Gastrorenal and splenorenal shunts}

Gastric varices that usually drain into the oesophageal or paraoesophageal veins can occasionally drain into the left renal vein via a gastrorenal shunt $[3,25,26]$ (Fig. 24). Among the extra-hepatic shunts, gastrorenal shunts are the most common [3]. They form generally through the lower branch of the left inferior phrenic vein, which opens directly into the renal vein (spleno-gastro-phreno-renal shunt), or through left adrenal vein [3]. The gastrocaval shunt drains through the upper branch of the inferior phrenic vein into the vena cava and is mostly continuous with the phrenicopericardial vein, which ultimately drains into the brachiocephalic vein [3].

Direct splenorenal shunts constitute a direct communication between the splenic vein and the left renal vein, sometimes through the splenic capsule. This type of direct portosytemic shunting is similar to the direct shunting of blood from posterior branch of the left gastric vein to para-

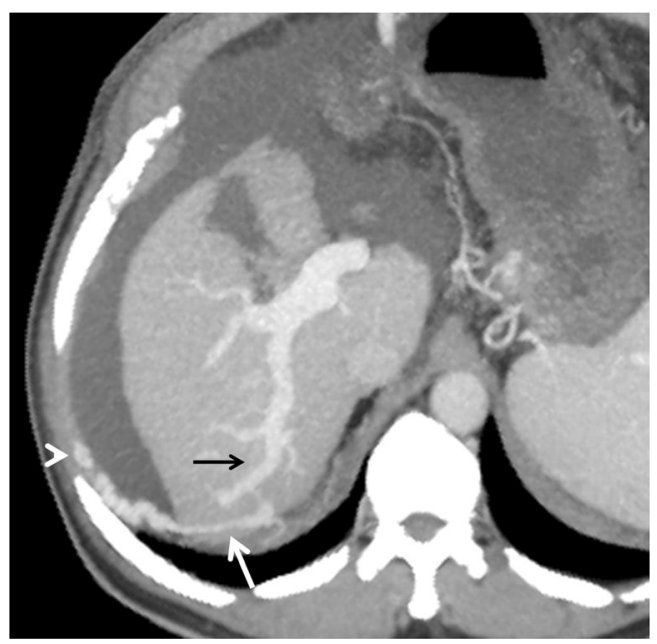

Fig. 22 Bare area shunt. An intrahepatic shunt (white arrow) is seen arising from a peripheral branch of right portal vein (black arrow) and draining into the intercostal veins (arrowhead) 


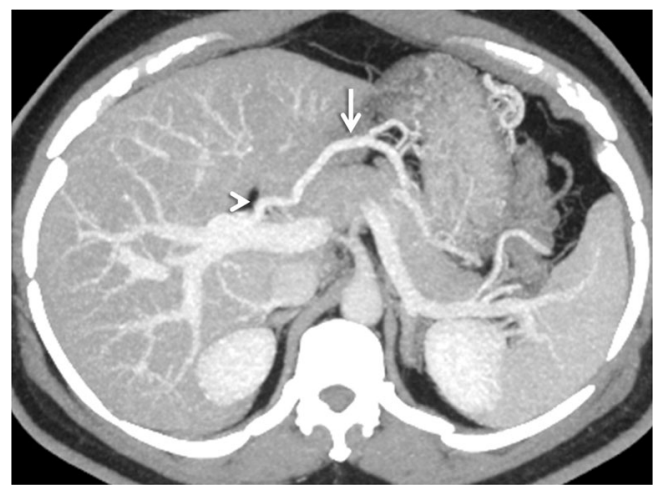

Fig. 23 Aberrant left gastric vein (arrow) draining into the portal vein (arrowhead)

oesophageal veins and azygos vein without formation of oesophageal varices.

Large spleno/gastro-renal shunts are often found in patients with recurrent or chronic hepatic encephalopathy, and BRTOof these has shown good results in improving the patient's neurological status [25, 65].

\section{Mesenterico-gonadal/renal/caval/iliac shunts}

Mesenteric collaterals arising from the SMV and IMV may unusually drain into the systemic circulation via large shunts $[48,49]$. Out of these, an ileocolic vein draining into the IVC or the right renal vein through the right gonadal vein (mesenterico- caval/gonadal varices) is the most frequently demonstrated pathway (Fig. 25) [3].

\section{Trans-splenic shunt}

Trans-splenic shunts (Fig. 26) are extremely rare, with only two case reports describing this entity. One of these was in an adult patient with compensated cirrhosis [14]. The other was in a study of children with extrahepatic portal venous

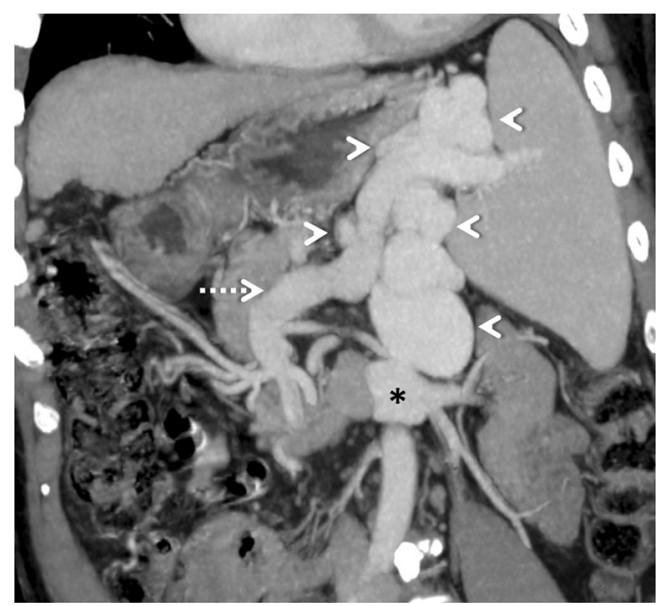

Fig. 24 Coronal MIP image demonstrating a dilated and tortuous splenorenal shunt (arrowheads) communicating between the splenic vein (interrupted arrow) and the left renal vein (asterisk)

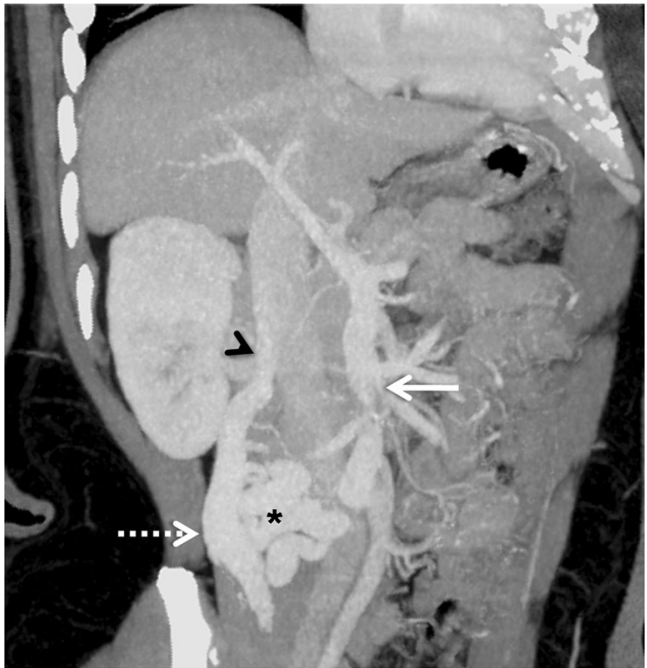

Fig. 25 Coronal MIP image showing a mesocaval shunt (interrupted arrow) communicating between the SMV (arrow) and IVC (arrowhead) with a bunch of mesenteric collaterals (asterisk)

obstruction [66], which concluded that trans-splenic shunts were uncommon but that their presence is seen in children with cirrhosis and PHTN. Associated intra-splenic collaterals can occasionally be found [14].

\section{Spleno-caval/phrenic/azygos shunt}

The splenic vein or the perisplenic collaterals communicate with the hypogastric vein and ultimately drain into the IVC (splenocaval shunt). The splenic vein can also communicate

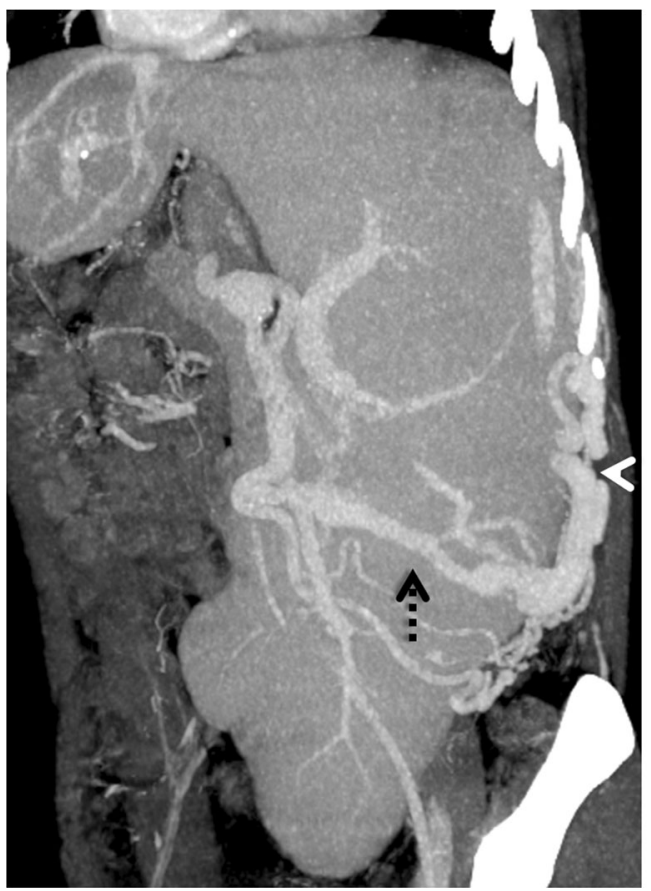

Fig. 26 Coronal oblique MIP image showing a trans-splenic shunt (interrupted arrow) draining into the intercostal vein (arrowhead) 
with the left inferior phrenic vein, hemiazygos vein or the posterior abdominal wall veins [4].

\section{Coronary/splenic-inferior pulmonary/inferior phrenic/intercostal veins}

The left gastric vein or splenic vein communicates with the inferior pulmonary vein, pericardiophrenic vein or to intercostal vein [4].

PSCV developing in the setting of Budd-Chiari syndrome and extrahepatic portal venous obstruction are a separate topic and have not been discussed here.

\section{Conclusion}

Unusual portosystemic collateral pathways are increasingly being encountered in the daily clinical practice. Since these could be an important cause of bleeding and hepatic encephalopathy, radiologists should be familiar with the imaging findings to effectively identify them and aid in therapeutic decision making. Also, preoperative knowledge of the anatomy and course of these uncommon portosystemiccollaterals is essential for interventional radiologists and surgeons to avoid inadvertent vascular injury during the procedures.

Open Access This article is distributed under the terms of the Creative Commons Attribution 4.0 International License (http:// creativecommons.org/licenses/by/4.0/), which permits unrestricted use, distribution, and reproduction in any medium, provided you give appropriate credit to the original author(s) and the source, provide a link to the Creative Commons license, and indicate if changes were made.

\section{References}

1. Cichoz-Lach H, Celinski K, Slomka M et al (2008) Pathophysiology of portal hypertension. J Physiol Pharmacol 59:231-238

2. Johns TN, Evans BB (1962) Collateral pathways in portal hypertension. Ann Surg 155:838-845

3. Sharma M, Rameshbabu CS (2012) Collateral pathways in portal hypertension. J Clin Exp Hepatol 2:338-52

4. Cho KC, Patel YD, Wachsberg RH, Seeff J (1995) Varices in portal hypertension: evaluation with CT. Radiographics 15(3):609-22

5. Moubarak E, Bouvier A, Boursier J et al (2012) Portosystemic collateral vessels in liver cirrhosis: a three-dimensional MDCT pictorial review. Abdom Imaging 37:746-66

6. Kang HK, Jeong YY, Choi JH et al (2002) Three-dimensional multidetector row CT portal venography in the evaluation of portosystemic collateral vessels in liver cirrhosis. Radiographics 22(5):1053-1061

7. Saad WE, Lippert A, Saad NE, Caldwell S (2013) Ectopic varices: anatomical classification, hemodynamic classification, and hemodynamic-based management. Tech Vasc Interv Radiol 16(2): $158-75$
8. Sabri SS, Saad WE (2011) Anatomy and classification of gastrorenal and gastrocaval shunts. Semin Interv Radiol 28(3):296-302

9. Itai Y, Saida Y, Irie T et al (2001) Intrahepatic portosystemic venous shunts: spectrum of CT findings in external and internal subtypes. J Comput Assist Tomogr 25:348-54

10. Ibukuro K, Tsukiyama T, Mori K et al (2000) Transhepatic portosystemic shunts: CT appearance and anatomic correlation. Am J Roentgenol 175:153-157

11. Ito K, Fujita T, Shimizu A et al (2009) Imaging findings of unusual intra and extrahepatic portosystemic collaterals. Clin Radiol 64:200-7

12. Kadoya M, Takashima T, Matsui O, Kitagawa K, Chohtoh S (1985) Unusual portosystemic collateral penetrating the liver parenchyma. Gastrointest Radiol 10(2):115-8

13. Gebrael J, Yu H, Hyslop WB (2013) Spontaneous portoazygos shunt in a patient with portal hypertension. J Radiol Case Rep 7:32-36

14. Philips CA, Anand L, Kumar KN, Kasana V, Arora A (2014) Rare, spontaneous trans-splenic shunt and intra-splenic collaterals with attendant splenic artery aneurysms in an adult patient with compensated cirrhosis and portal hypertension. Gastroenterol Rep (Oxf)

15. Schepis F, Cammà C, Niceforo D, Magnano A, Pallio S, Cinquegrani $\mathrm{M}$ et al (2001) Which patients with cirrhosis should undergo endoscopic screening for esophageal varices detection? Hepatology 33(2):333-8

16. Merli M, Nicolini G, Angeloni S, Rinaldi V, De Santis A, Merkel C et al (2003) Incidence and natural history of small esophageal varices in cirrhotic patients. J Hepatol 38(3):266-72

17. Arakawa M, Masuzaki T, Okuda K et al (2002) Pathomorphology of esophageal and gastric varices. Semin Liver Dis 22:73-82

18. Sarin SK, Lahoti D, Saxena SP et al (1992) Prevalence, classification and natural history of gastric varices: a long-term follow up study in 568 portal hypertension patients. Hepatology 16:1343-1349

19. Hashizume M, Sugimachi K (1995) Classification of gastric lesions associated with portal hypertension. J Gastroenterol Hepatol 10:339-343

20. Greig JD, Garden OJ, Anderson JR et al (1990) Management of gastric variceal haemorrhage. Br J Surg 77:297-299

21. Kiyosue H, Mori H, Matsumoto S et al (2003) Transcatheter obliteration of gastric varices. Part 1. Anatomic classification. Radiographics 23:911-920

22. Henry Z, Uppal D, Saad W, Caldwell S (2014) Gastric and ectopic varices. Clin Liver Dis 18(2):371-88

23. Irani S, Kowdley KV, Kozarek RA (2011) Gastric varices: an updated review of management. J Clin Gastroenterol 45:133-148

24. Chikamori F, Kuniyoshi N, Kawashima T et al (2008) Gastric varices with gastrorenal shunt: combined therapy using transjugular retrograde obliteration and partial splenic embolization. AJR Am J Roentgenol 191:555-559

25. Kiyosue H, Tanoue S, Kondo Y et al (2011) Balloon-occluded retrograde transvenous obliteration of complex gastric varices assisted by temporary balloon occlusion of the splenic artery. J Vasc Interv Radiol 22:1045-1048

26. Saraswat VA, Verma A (2012) Gluing gastric varices in 2012: lessons learnt over 25 years. J Clin Exp Hepatol 1:55-69

27. Hashimoto N, Akhoshi T, Yoshida D et al (2010) The efficacy of balloon- occluded retrograde transvenous obliteration on small intestinal variceal bleeding. Surgery 148:145-150

28. Kocher N, Tripathy D, McAvoy NC et al (2008) Bleeding ectopic varices in cirrhosis: the role of transjugular intra-hepatic portosystemic stent shunts. Aliment Pharmacol Ther 28:294-303

29. Onozato Y, Kakizaki S, Lizuka $\mathrm{H}$ et al (2007) Ectopic varices rupture in the gastroduodenal anastomosis successfully treated with $\mathrm{N}$ butyl-2-cyanoacrylate injection. Acta Med 61:361-365

30. Kanagawa H, Mima S, Kouyama H et al (1996) Treatment of gastric fundal varices by balloon-occluded retrograde transvenous obliteration. J Gastroenterol Hepatol 11:51-58 
31. Hashizumi M, Tanoue K, Ohta M et al (1993) Vascular anatomy of duodenal varices: angiographic and histopathological assessment. Am J Gastroenterol 88:1942-1945

32. Wang CS, Jeng LB, Chen MF (1995) Duodenal variceal bleeding successfully treated by mesocaval shunt after failure of sclerotherapy. Hepatogastroenterology 42:59-61

33. Nardone G, Budillon G (1991) Treatment of duodenal varices by endoscopic sclerotherapy. Gastrointest Endosc 37:407-408

34. Shibata D, Brophy DP, Gordon FD et al (1999) Transjugular Intrahepatic portosystemic shunt for treatment of bleeding ectopic varices with portal hypertension. Dis Colon Rectum 42(12):1581-1585

35. Sato T (2010) Transabdominal color Doppler ultrasonography for the diagnosis of small intestinal and vesical varices in a patient successfully treated with percutaneous transhepatic obliteration. Clin J Gastroenterol 3:214-218

36. Francois F, Tadros C, Diehl D (2007) Pan-colonic varices and Idiopathic portal hypertension. J Gastrointestin Liver Dis 16(3):325-328

37. Ito K, Shiraki K, Sakai T, Yoshimura H, Nakano T (2005) Portal hypertensive colopathy in patients with liver cirrhosis. World $\mathrm{J}$ Gastroenterol 11(20):3127-30

38. McHugh PP, Jeon H, Gedaly R et al (2008) Vaginal varices with massive hemorrhage in a patient with nonalcoholic steatohepatitis and portal hypertension: successful treatment with liver transplantation. Liver Transpl 14(10):1538-1540

39. Chan G, Taqi A, Drage M, Quan D (2013) A case report of massive vaginal variceal hemorrhage in a patient with cirrhosis secondary to nonalcoholic steatohepatitis unresolved even after successful liver transplantation. Transplant Proc 45(2):835-7

40. Orlando G, Goffette P, Geubel A et al (2005) Vaginal bleeding complicating portal hypertension: a particular entity-report of two cases and review of the literature. Transpl Int 18:1382-4

41. Gaspar Y, Detry O, de Leval J (2001) Vesical varices in a patient with portal hypertension. N Engl J Med 345(20):1503-1504

42. Lugagne PM, Castaing D, Conort P (1992) Portal hypertension: a rare cause of hematuria. Prog Urol 2(2):294-298

43. Loganathan G, Shyamkumar NK, Kurian G et al (2000) Vesical varix in cirrhosis of liver. Indian J Gastroenterol 19(4):193-194

44. Chawla Y, Dilawari JB, Katariya S (1994) Gallbladder wall varices in portal vein thrombosis. AJR Am J Roentgenol 162(3):643-645

45. Nagahiro I, Toda D, Andou A, Shimizu N (2007) A case of bronchial varices due to extrahepatic portal hypertension. Respiration 74(4):460-1

46. Youssef AI, Escalante-Glorsky S, Bonnet RB, Chen YK (1994) Hemoptysis secondary to bronchial varices associated with alcoholic liver cirrhosis and portal hypertension. Am J Gastroenterol 89(9): $1562-3$

47. Mansilla AV, Ball D, Putman SG, Cohen GS, Krachman S, Black M (1999) Massive hemoptysis secondary to bronchial collaterals: treatment with use of TIPS and embolization. J Vasc Interv Radiol 10(3):372-4

48. Agarwal A, Jain M (2008) Multidetector CT portal venography in evaluation of portosystemic collateral vessels. J Med Imaging Radiat Oncol 52(1):4-9

49. Ibukuro K, Tsukiyama T, Mori K et al (1998) Veins of Retzius at CT during arterial portography: anatomy and clinical importance. Radiology 209(3):793-800
50. Bataille L, Baillieux J, Remy P, Gustin RM, Denié C (2004) Spontaneous rupture of omental varices: an uncommon cause of hypovolemic shock in cirrhosis. Acta Gastroenterol Belg 67(4):351-4

51. Ragupathi K, Bloom A, Pai N (1985) Hemoperitoneum from ruptured omental varices. J Clin Gastroenterol 7(6):537-8

52. Mitchell AW, Jackson JE (2000) Trans-anastomotic porto-portal varices in patients with gastrointestinal haemorrhage. Clin Radiol 55(3):207-11

53. Hashimoto M, Heianna J, Yasuda K, Tate E, Watarai J, Shibata S et al (2005) Portal flow into the liver through veins at the site of biliary-enteric anastomosis. Eur Radiol 15(7):1421-5

54. Dhiman RK, Saraswat VA, Choudhuri G et al (1999) Endosonographic, endoscopic and histologic evaluation of alterations in the rectal venous system in patients with portal hypertension. Gastrointest Endosc 49(2):218-227

55. Park JH, Cha SH, Han JK, Han MC (1990) Intrahepatic portosystemic venous shunt. AJR Am J Roentgenol 155:527-528

56. Yoshimitsu K, Andou H, Kudo S, Matsuo Y, Matsumoto S, Nakao T, Shimoda Y (1993) Multiple intrahepatic portosystemic venous shunts: treatment by portal vein embolization. Cardiovasc Intervent Radiol 16(1):49-51

57. Sappey C (1883) Memorie sur les veines portes accessories. J Anat Physiol 19:517-524

58. Singla V, Galwa RP, Saxena AK, Khandelwal N (2008) Cruveilhier Baumgarten syndrome with giant paraumbilical vein. J Postgrad Med 54(4):328-9

59. Arora A, Mukund A, Patidar Y, Khera P (2013) CruveilhierBaumgarten syndrome: intriguing for the hepatologist, caveat for a surgeon. ANZ J Surg 83(1-2):86-7

60. Cho YJ, Kim HC, Kim YW, Hur S, Jae HJ, Chung JW (2014) Percutaneous access via the recanalized paraumbilical vein for varix embolization in seven patients. Korean J Radiol 15(5):630-6

61. Lim LG, Lee YM, Tan L et al (2009) Percutaneous paraumbilical embolization as an unconventional and successful treatment for bleeding jejunal varices. World J Gastroenterol 15(30):3823-3826

62. Ishikawa T, Clark RA, Tokuda M, Ashida H (1983) Focal contrast enhancement on hepatic CT in superior vena caval and brachiocephalic vein obstruction. AJR 140:337-338

63. van Steenbeek FG, van den Bossche L, Leegwater PA, Rothuizen J (2012) Inherited liver shunts in dogs elucidate pathways regulating embryonic development and clinical disorders of the portal vein. Mamm Genome 23(1-2):76-84

64. Hishiki T, Ohsone Y, Tatebe S et al (2006) A neonatal case of thoracoabdominal duplication associated with right congenital diaphragmatic hernia, absent inferior vena cava, and congenital portoazygos shunt: etiopathogenesis and surgical management. J Pediatr Surg 41(11):e21-24

65. Mukund A, Rajesh S, Arora A, Patidar Y, Jain D, Sarin SK (2012) Efficacy of balloon-occluded retrograde transvenous obliteration of large spontaneous lienorenal shunt in patients with severe recurrent hepatic encephalopathy with foam sclerotherapy: initial experience. J Vasc Interv Radiol 23(9):1200-6

66. Barakat M (2002) Doppler sonographic findings in children with idiopathic portal vein cavernous deformity and variceal hemorrhage. J Ultrasound Med 21:825-30 